\title{
Assessment of ERBB2 and EGFR gene amplification and protein expression in gastric carcinoma by immunohistochemistry and fluorescence in situ hybridization
}

\author{
Wang YK*, Gao CF, Yun T, Chen Z, Zhang XW, LV XX, Meng NL and Zhao WZ
}

\begin{abstract}
Background: The goal of this study was to investigate ERBB2(HER2) and EGFR gene amplification and protein expression in gastric cancer. Fluorescence in situ hybridization (FISH) and immunohistochemistry were used to analyze ERBB2 and EGFR gene amplification and protein expression in 69 cases of gastric cancer.

Results: FISH analysis revealed that $20.3 \%$ of the cases exhibited ERBB2 gene amplification. Increases in ERBB2 copy number and gene amplification were present in 52.2\% of the samples. Expression of the ERBB2 protein was observed in $42.0 \%$ of cases. FISH analysis detected EGFR gene amplification in $29.0 \%$ of samples. Increases in EGFR copy number and gene amplification occurred in $57.9 \%$ of samples, and EGFR protein expression was present in $52.2 \%$ of samples. Both ERBB2 and EGFR gene amplification were 3 cases (4.3\%), but abnormalities in both ERBB2 and EGFR gene copy number were present $36.2 \%$ of samples. ERBB2 and EGFR gene amplification were significantly associated with the depth of tumor invasion $(P<0.05)$ and lymph node metastasis $(P<0.05)$, but not with sex, age, or histological type $(P>0.05)$.
\end{abstract}

Conclusions: Our data indicated that ERBB2 and EGFR genetic abnormalities were associated with the prognosis of gastric cancer. Clinical assessment of ERBB2 and EGFR amplification may represent an important factor for the development of personalized treatment programs for gastic cancer.

\section{Introduction}

Overexpression of the human epidermal growth factor receptor 2 (ERBB2(HER2)), also known as C-erbB-2, can lead to the activation of cellular signal transduction systems, resulting in the cellular transformation and cell proliferation events associated with cancer [1]. ERBB2 is very similar in structure to the epidermal growth factor receptor $(E G F R)$, with approximately $95 \%$ homology between the 260 amino acid intracellular region (aa 727986), which contains the EGFR tyrosine kinase domain, and the corresponding domain in EGFR. Both ERBB2 and $E G F R$ are membrane-associated tyrosine kinases and contain three functional domains: the extracellular ligand binding domain (aa 1-632), a lipophilic

\footnotetext{
* Correspondence: wyk_150@163.com

Department of Pathology, The 150 Centre Hospital of Chinese PLA, Medical Center of Jinan Military Region, Luoyang 471031, China
}

transmembrane segment (aa 633-654), and a cytoplasmic domain that exhibits tyrosine kinase activity (aa 655-1234) [2,3], ERBB2 is frequently unregulated in human cancers such as breast cancer [4], ovarian cancer [5], and so on. High expression level of ERBB2 has been significantly correlated with increased tumor invasion, metastasis, resistance to chemotherapy, and poor prognosis of patients [6]. However, a lack of reliable and accurate methods to assess the relationship between $E G F R$ and ERBB2 gene status and protein expression in gastric cancer has limited correlative assessments with clinical parameters, including survival and sensitivity to targeted agents. Therefore, in the present study, we utilized fluorescence in situ hybridization (FISH) to assess amplification of the ERBB2 and EGFR genes in gastric cancer patient samples. We combined this data with results from histopathological and immunohistochemical analyses to determine the relationship between ERBB2 
and EGFR expression status and clinicopathological variables in gastric cancer.

\section{Materials and methods \\ Patients and tumor samples}

A total of 69 gastric cancer patients who underwent radical gastrectomy at the Liberation Army No. 150 Central Hospital between July, 2008 and March, 2010 were included in this study. Tumor subtypes included 16 papillary adenocarcinomas, 14 tubular gland cancers, 15 mucinous adenocarcinomas, 13 poorly differentiated adenocarcinomas, and 11 signet ring cell carcinomas. The average age of the patients at the time of surgery was 59.2 years (range, 31-76 years). Tumor specimens were collected after obtaining informed consent from the patients in accordance with institutional guidelines. The samples were fixed in $10 \%$ neutral formalin in preparation for further studies.

\section{FISH analysis}

$E R B B 2$ and $E G F R$ gene amplification were analyzed by FISH using the Vysis Path Vysion ERBB2/DNA probe kit and the LSI EGFR SpectrumOrange/CEP 7 SpectrumGreen probe, respectively, according to manufacturer's instructions (Abbott Molecular, Abbott Park, IL, USA). Briefly, samples fixed in $10 \%$ formalin and embedded in paraffin were cut into $4 \mu \mathrm{m}$ sections and incubated overnight at $56{ }^{\circ} \mathrm{C}$. Slides were dewaxed in xylene and dehydrated in 100\% alcohol for $5 \mathrm{~min}$, followed by air drying. The slides were then incubated in proteinase $\mathrm{K}$ solution $(0.2 \mathrm{mg} / \mathrm{mL}$ in $2 \times \mathrm{SSC})$ at $37{ }^{\circ} \mathrm{C}$ for $15 \mathrm{~min}$, washed with $2 \times \mathrm{SSC}$ ( $\mathrm{pH} 7.0)$, and sequentially dehydrated in $70 \%, 85 \%$, and $100 \%$ ethanol. After the application of $10 \mu \mathrm{l}$ of probe to the target area of the slide, a coverslip was placed over the sample and sealed. Following denaturation at $73{ }^{\circ} \mathrm{C}$ for $5 \mathrm{~min}$, the slides were allowed to hybridize overnight at $37{ }^{\circ} \mathrm{C}$ in a humidified chamber. After hybridization, the slides were washed in $0.4 \times$ SSC containing $0.3 \%$ Nonidet P40 at 65 ${ }^{\circ} \mathrm{C}$ for 2 min and rinsed twice in $2 \times$ SSC containing $0.1 \%$ Nonidet P 40 for $2 \mathrm{~min}$. The slides were then immersed in $70 \%$ ethanol for $3 \mathrm{~min}$ and dried at room temperature. After the slides were counterstained with 4', 6-Diamidino-2-phenylindole dihydrochloride (DAPI), they were observed under a fluorescence microscope (Carl Zeiss, Goettingen, Germany)[7].

$E R B B 2$ levels were reported as $E R B B 2$ gene: $C E P 17$ ratios in order to normalize values to the total number of chromosomes within each cell. Amplification was defined as an $E R B B 2$ gene/CEP 17 ratios greater than or equal to 2.0 [8]. EGFR gene amplification was defined based on the criteria suggested by M Varella-Garcia, et al [9]. Several FISH patterns were identified for EGFR: (1)EGFR FISH-positive: (a) at least 15 copies of the
EGFR signals in $\geq 10 \%$ of tumour cells (b) Specimens that have $\geq 40 \%$ of cells displaying $\geq 4$ copies of the EGFR signal.(c) EGFR/CEP7 ratio 1, but the presence of gene cluster ( $\geq 4$ spots) in $\geq 10 \%$ of tumour cells;(d) $E G F R / C E P 7$ ratio $\geq 2$ and the presence of gene cluster ( $\geq 4$ spots) in $\geq 10 \%$ of tumour cells; (2) EGFR FISHnegative: Specimens that do not display gene amplification according to the criteria defined above and with $<40 \%$ of cells displaying $\geq 4$ copies of the EGFR signal.

\section{Immunohistochemistry}

$E R B B 2$ and $E G F R$ protein expression were evaluated by immunohistochemistry using the HercepTest ${ }^{\mathrm{TM}}$ and $E G F R$ pharmDx ${ }^{\mathrm{TM}}$ kits, respectively, according to the manufacturer's recommended protocols (DAKO, Carpinteria, CA, USA). Two pathologists independently scored slides as $0,1^{+}, 2^{+}$, or $3^{+}$according to the guidelines provided by DAKO. As defined in the manufacturer's instructions, scores of 0 or $1^{+}$were considered negative, a score of $2^{+}$was weakly positive, and a score of $3^{+}$was strongly positive.

\section{Statistical analysis}

The SPSS 13.0 statistical package (SPSS, Inc., Chicago, IL, USA) was used for all statistical analyses. A $\chi^{2}$ test was used for comparisons with ERBB2 and EGFR gene amplification. $P$-values less than 0.05 were considered to be statistically significant.

\section{Results}

ERBB2 gene amplification and protein expression

Of the 69 gastric tumors, 14 (20.3\%) cases exhibited $E R B B 2$ gene amplification (Figure 1A). Of the remaining 55 cases without $E R B B 2$ gene amplification, the copy number was increased in 22 cases. Therefore, ERBB2 copy number increases or gene amplification were observed in a total of $52.2 \%(36 / 69)$ of the samples. The $E R B B 2$ protein was expressed (Figure 1B) in $42.0 \%$ (29/ 69 ) of the samples. Overexpression of the ERBB2 protein, evident as immunostaining scores of $2^{+}$or $3^{+}$, was frequently associated with $E R B B 2$ gene amplification, as $E R B B 2$ gene amplification was present in 7 of 9 tumors with a score of $2^{+}$and in 4 of 4 tumors with a score of $3^{+}$. Tumors that exhibited a staining score of $1^{+}$were classified as having a low amplification rate, as only 3 of 16 samples exhibited ERBB2 amplification. Samples with scores of $1^{+}$exhibited a significant difference in levels of $E R B B 2$ amplification in comparison to samples with scores of $2^{+}$and $3^{+}(P<0.05$, Table 1$)$.

\section{EGFR gene amplification and protein expression}

Of the 69 patient samples, 29.0\% (20/69) exhibited EGFR gene amplification (Figure 1C). Interestingly, overexpression of the EGFR protein in the absence of EGFR 


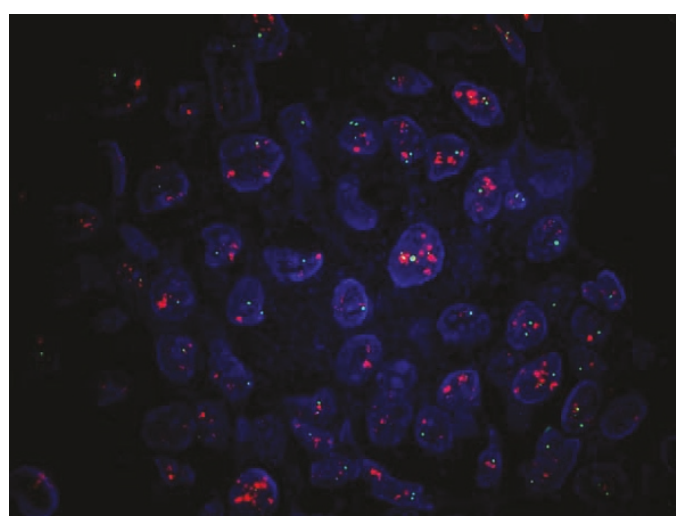

Figure1.(A)

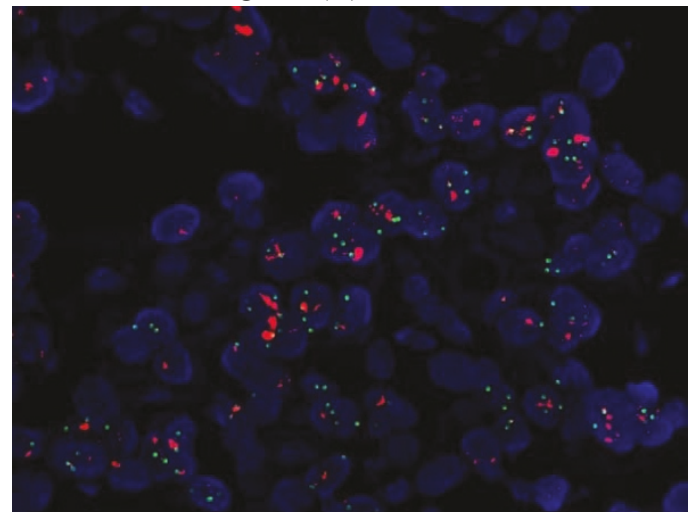

Figure1.(C)

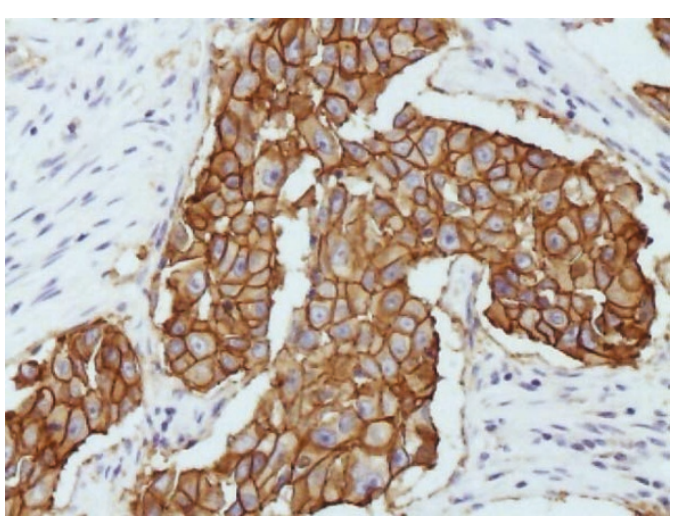

Figure1.(B)

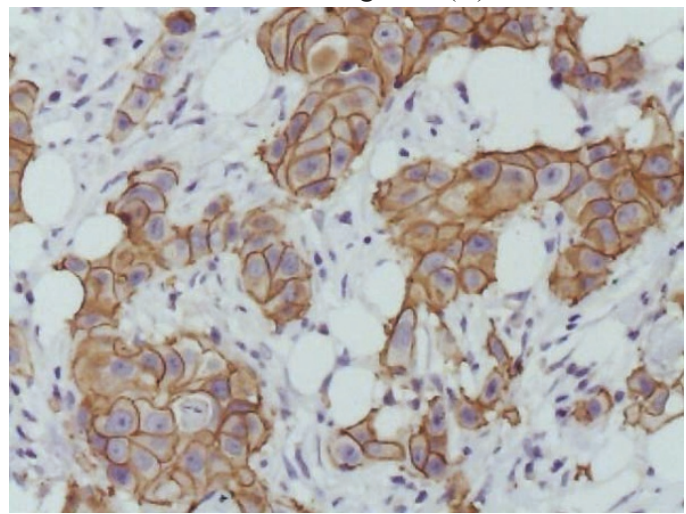

Figure1.(D)

Figure 1 ERBB2 and EGFR gene amplification and protein expression in gastric cancer samples. (A) Representative image showing ERBB2 gene amplification in a gastric adenocarcinoma sample analyzed by FISH. The ratio of red to green signal is greater than 2, indicative of ERBB2 gene amplification (magnification, 1000 x). (B) Representative image showing ERBB2 protein expression analyzed by $\mathrm{HC}$ in a poorly-differentiated gastric adenocarcinoma (IHC score, $3^{+}$; magnification, $200 \times$ ). (C) Representative image showing EGFR gene amplification in a gastric adenocarcinoma sample analyzed by FISH. The green signal corresponds to chromosome 7, and the red signal corresponds to EGFR. EGFR gene amplification is visible as red clustering (magnification, $1000 \times$ ). (D) Representative image showing EGFR protein expression analyzed by IHC in a poorly-differentiated gastric adenocarcinoma (IHC score, $3^{+}$; magnification, $200 \times$ ).

gene amplification was observed more frequently than expected. A total of 40/69 cases exhibited increases in EGFR gene copy number in the all samples. The EGFR protein was expressed in $52.2 \%(36 / 69)$ of patient samples (Figure 1D). Immunohistochemical analysis revealed that samples with EGFR protein expression scores of $3^{+}$

Table 1 Comparison of ERBB2 gene amplification and protein expression in 69 cases of gastric cancer

\begin{tabular}{lcccc}
\hline IHC score & $\begin{array}{c}\text { IHC } \\
\mathbf{n}(\%)\end{array}$ & $\begin{array}{c}\text { FISH } \\
\mathbf{n}(\%)\end{array}$ & $\chi^{2}$ & P-value \\
\hline 0 & $40(57.9 \%)$ & $55(82.7 \%)$ & & \\
$1^{+}$ & $16(23.3 \%)$ & $3(4.3 \%)^{*}$ & 12.461 & 0.000 \\
$2^{+}$ & $9(13.0 \%)$ & $7(10.1 \%)$ & & \\
$3^{+}$ & $4(5.8 \%)$ & $4(5.8 \%)$ & & \\
Total positive cases & $29(42.0 \%)$ & $14(20.3 \%)$ & & \\
\hline
\end{tabular}

* In comparison to FISH results from combined samples with scores of $2^{+}$and $3^{+}$. IHC, immunohistochemistry; FISH, fluorescence in situ hybridization; $\mathrm{n}$, number of positive samples. and $2^{+}$exhibited significantly higher levels of gene amplification than those with scores of $1^{+}$(5/5 and 10/ 11 vs. 5/20, respectively; $P<0.05$; Table 2 ).

\section{Relationship between ERBB2 and EGFR gene} abnormalities in gastric cancer

$E R B B 2$ copy number alterations and gene amplification occurred in a total of $52.2 \%(36 / 69)$ of patient samples. EGFR copy number alterations and gene amplification occurred in a total of $57.9 \%(40 / 69)$ of patient samples. Both $E R B B 2$ and EGFR gene amplification were 3 cases (4.3\%), but abnormalities in both ERBB2 and EGFR gene copy number were present $36.2 \%$ of samples, indicating that abnormalities in the two genes may be correlated.

\section{Correlation between ERBB2 and EGFR gene amplification} and clinicopatholigical parameters in gastric cancer $E R B B 2$ and EGFR gene amplification were not associated with sex, age, or histological type $(P>0.05)$ in 
Table 2 Comparison of EGFR gene amplification and protein expression in 69 cases of gastric cancer

\begin{tabular}{lcccc}
\hline IHC score & $\begin{array}{c}\text { IHC } \\
\mathbf{n}(\%)\end{array}$ & $\begin{array}{c}\text { FISH } \\
\mathbf{n}(\%)\end{array}$ & $\chi^{2}$ & $P$-value \\
\hline 0 & $33(47.8 \%)$ & $49(71.0 \%)$ & & \\
$1^{+}$ & $20(29.0 \%)$ & $5(7.2 \%)^{*}$ & 17.016 & 0.000 \\
$2^{+}$ & $11(15.9 \%)$ & $10(14.5 \%)$ & & \\
$3^{+}$ & $5(7.3 \%)$ & $5(7.2 \%)$ & & \\
Total positive cases & $36(52.2 \%)$ & $20(29.0 \%)$ & & \\
\hline
\end{tabular}

* In comparison to FISH results from combined samples with scores of $2^{+}$and $3^{+}$. IHC, immunohistochemistry; FISH, fluorescence in situ hybridization; $\mathrm{n}$, number of positive samples.

gastric cancer samples. However, amplification of both $E R B B 2$ and EGFR were significantly associated with the depth of invasion of the tumor and with lymph node metastasis. In our search, $24.4 \%(10 / 41)$ and $34.1 \%(14 /$ 41) of patients with lymph node metastases harbored $E R B B 2$ and EGFR gene amplification, respectively. $(P<$ 0.05, Table 3).

\section{Discussion}

$E G F R$ belongs to a family of four related receptors that includes the EGFR (HER1), ERBB2, HER3, and HER4 receptors [10]. The EGFR gene is located in the short arm of human chromosome 7 and produces a glycoprotein with a molecular weight of $170 \mathrm{kDa}$ with high affinity for the EGF ligand [11]. EGFR mediates multiple signal transduction pathways and, thereby, connects extracellular signaling to intracellular changes in gene expression that modulate cellular growth and differentiation. Currently, EGFR and ERBB2 are the best characterized of the $H E R$ family receptors. However, little is known regarding the expression and function of these receptors in gastric cancer.

In recent years, interest has grown in understanding the relationship between the biological characteristics of gastric cancer and the association of these characteristics with the clinical outcomes of the disease. Current studies have focused on understanding the molecular basis of gastric cancer in order to help achieve accurate diagnoses and to better choose effective treatment options. With the advent of novel targeted therapeutics, these molecular characteristics may be important for obtaining more effective therapeutic outcomes. Presently, much of the available knowledge regarding EGFR and $E R B B 2$ expression as well as their biological function in gastric cancer has come from countries other than China. Research techniques for characterization of $E G F R$ and ERBB2 expression have included immunohistochemistry (IHC), chromogenic in situ hybridization (CISH), and FISH. Using kits approved by the United States Federal Drug Administration for IHC (HercepTest $^{\mathrm{TM}}$ and EGFR pharmDx ${ }^{\mathrm{TM}}$ ) and FISH (Path Vysion ${ }^{\mathrm{TM}}$ ), we have analyzed EGFR and ERBB2 protein expression and gene status in Chinese gastric cancer patients in order to provide more accurate reference data for future studies in the Chinese population.

Table 3 Association of ERBB2 and EGFR gene amplification with clinicopathological parameters in 69 cases of gastric cancer

\begin{tabular}{|c|c|c|c|c|c|c|c|}
\hline Parameter & $\mathrm{n}^{*}$ & $\begin{array}{c}\text { ERBB2 } \\
\text { Amp. * } \\
\text { Positive (\%) }\end{array}$ & $\chi^{2}$ & $P$-value & $\begin{array}{c}\text { EGFR } \\
\text { Amp. * } \\
\text { Positive (\%) }\end{array}$ & $\chi^{2}$ & $P$-value \\
\hline \multicolumn{8}{|l|}{ Sex } \\
\hline Male & 41 & $8(19.5)$ & 0.316 & 0.574 & $11(26.8)$ & 0.261 & 0.609 \\
\hline Female & 28 & $4(14.3)$ & & & $6(21.4)$ & & \\
\hline \multicolumn{8}{|l|}{ Age } \\
\hline$\geq 60$ & 36 & $7(19.4)$ & 0.221 & 0.638 & $10(27.8)$ & 0.400 & 0.527 \\
\hline$<60$ & 33 & $5(15.2)$ & & & $7(21.2)$ & & \\
\hline \multicolumn{8}{|l|}{ Histological type } \\
\hline Papillary adenocarcinoma & 16 & $2(12.5)$ & & & $3(18.8)$ & & \\
\hline Tubular adenocarcinoma & 14 & $2(14.3)$ & & & $3(21.4)$ & & \\
\hline Mucinous adenocarcinoma & 15 & $3(20.0)$ & 0.729 & 0.948 & $4(26.7)$ & 0.714 & 0.950 \\
\hline Poorly differentiated adenocarcinoma & 13 & $3(23.1)$ & & & $4(30.8)$ & & \\
\hline Signet ring cell carcinoma & 11 & $2(18.2)$ & & & $3(27.3)$ & & \\
\hline \multicolumn{8}{|l|}{ Gastric cancer staging } \\
\hline $\mathrm{T} 1 / \mathrm{T} 2$ & 25 & $1(4.0)$ & 4.894 & 0.027 & $2(7.7)$ & 5.845 & 0.016 \\
\hline $\mathrm{T} 3 / \mathrm{T} 4$ & 44 & $11(25.0)$ & & & 15(34.1) & & \\
\hline \multicolumn{8}{|l|}{ Lymph node metastasis } \\
\hline Present & 41 & $10(24.4)$ & 6.264 & 0.012 & $14(34.1)$ & 4.920 & 0.027 \\
\hline Absent & 28 & 2(7.1) & & & $3(10.7)$ & & \\
\hline
\end{tabular}

\footnotetext{
* $n$, number of samples; Amp., amplification.
} 
$E G F R$ and $E R B B 2$ expression in gastric cancer has been reported in many past studies. IHC was first used in 1986 to detect $E R B B 2$ expression in gastric cancer [12], which was followed by a large number of similar reports. Reported rates of $E R B B 2$ gene expression in gastric cancer range were from $9 \%$ to $38 \%$. Moreover, the correlation between $E G F R / E R B B 2$ expression in gastric cancer and prognosis remains controversial. In the present study, the ERBB2 protein was expressed in $42.0 \%(29 / 69)$ of gastric tumors, and ERBB2 gene amplification occurred in $20.3 \%(14 / 69)$ of tumors. Of 41 patients with lymph node metastases, ERBB2 gene amplification was present in $24.4 \%(10 / 41)$ of the cases. The EGFR protein was expressed in $52.2 \%(36 / 69)$ of gastric tumors, and EGFR gene amplification occurred in $29.0 \%(20 / 69)$ of tumors. Of patients with lymph node metastases, EGFR gene amplification was present in $34.1 \%(14 / 41)$ of the cases. These results suggest that $E R B B 2$ and EGFR gene amplification are positively associated with $E R B B 2$ and $E G F R$ protein expression. Furthermore, a higher frequency of $E R B B 2$ and $E G F R$ gene amplification is present in gastric cancer patients with lymph node metastases. EGFR and ERBB2 expression in gastric epithelial cells are indicators of malignancy and may prove useful as markers for poor prognosis in gastric cancer.

At present, pathological examination is primary method used to assess the ERBB2 and EGFR status of tumor cells. In particular, IHC and FISH are commonly used in clinical settings. IHC is currently the most widely-used method, and kits are commercially-available for semi-quantitative detection of both $E R B B 2$ and $E G F R$. Importantly, the higher levels of ERBB2 expression are associated with improved benefit of ERBB2-targeted anticancer drugs [13]. Application of IHC to evaluate the expression of ERBB2 in tumor cells has limitations, as the determination of staining is partially subjective, as opposed to strictly quantitative. In contrast, results from the FISH are substantially less subjective than IHC, while maintaining sensitivity and specificity. Furthermore, the quantitative nature of FISH results can effectively reduce operator interference and inter-laboratory variations [14]. In the present study, FISH revealed that $E R B B 2$ gene amplification was present in 4 of 4 cases with an IHC score of $3^{+}$, in 7 of 9 cases with an IHC score of $2^{+}$, and in only 3 of 16 cases with an IHC score of $1^{+}$. These results indicated that a statistically significant difference in ERBB2 gene amplification was present between the high $\left(2^{+}\right.$and $\left.3^{+}\right)$and low $\left(1^{+}\right)$IHC score groups $(P<0.05)$. Similar results were observed with respect to EGFR gene amplification. EGFR gene amplification was observed in 5 of 5 samples with an IHC score of $3^{+}$, in 10 of 11 samples with a score of $2^{+}$, and in 5 of 20 samples with a score of $1^{+}$, which represented a significant difference between the high $\left(2^{+}\right.$and $\left.3^{+}\right)$and low $\left(1^{+}\right)$scores $(P<0.05)$. Based on these results, the FISH assay could prove to be truly valuable for determination of ERBB2 and EGFR expression in clinical practice.

In recent years, new developments in cancer biology have led to the emergence of novel molecular-targeted therapeutics. These targeted drugs selectively act on cancer cells at the molecular, biochemical, and genetic levels, specifically targeting abnormal cells, with minimal effects on the function of normal cells. For example, EGFR inhibitors have been used to block EGFR activity and, thereby, increase the radiosensitivity of tumor cells [15]. This phenomenon can lead to improvement of the efficacy of radiotherapy, likely because inhibition of EGFR signaling in tumor cells decreases cell proliferation, accelerates apoptosis, interferes with the cell cycle, and extends the time required for DNA repair after radiation [16]. In the present study, FISH analysis revealed that EGFR gene amplification was present in $24.6 \%$ of the cases analyzed, and IHC showed that the EGFR protein was expressed in $52.2 \%$ of the cases. These results suggest that in some radiation-resistant gastric cancer cases, targeting of EGFR for radiation sensitization therapy may have important clinical value.

Co-expression of ERBB2 and EGFR may have synergistic effects on the progression of gastric cancer [17]. ERBB2 gene amplification was observed in20.3\% (14/69) of gastric cancer patients, including $24.4 \%$ (10/41) of the 41 patients with lymph node metastases and only $7.1 \%$ $(2 / 28)$ of patients without lymph node metastases, representing a significant difference $(P<0.05)$. EGFR gene amplification was present in $29.0 \%(20 / 69)$ of gastric cancers, including $34.1 \%(14 / 41)$ of patients with lymph node metastases and $10.7 \%(3 / 28)$ of patients without lymph node metastases, again representing a significant difference $(P<0.05)$. ERBB2 and EGFR gene amplification were also significantly related. Increased $E R B B 2$ copy number and gene amplification were present in a total of $57.9 \%$ (40/69) of samples. However, Both ERBB2 and EGFR gene amplification of gastric tumors were 3 cases (4.3\%), but abnormalities both ERBB2 and EGFR gene copy number were present in $36.2 \%$ of samples. These results suggest that alterations in ERBB2 or EGFR gene status in gastric cancer are common events that frequently occur within the same tumor.

In summary, ERBB2 and EGFR are transmembrane tyrosine kinases that can promote tumorigenesis and tumor progression. Expression of ERBB2 and EGFR appear to be closely related, and one or both proteins are frequently overexpressed in gastric epithelial cancer cells. Furthermore, the degree of expression is correlated with tumor invasion, progression, and patient survival, suggesting that these genes may represent important 
indicators of poor prognosis. EGFR overexpression in gastric cancer commonly leads to radiation resistance. Therefore, EGFR-targeted radiosensitization treatments may have important clinical value for treatment of gastric cancer.

\section{Acknowledgements}

We would like to thank Professor Yan-qing Ding (Southern Medical University) faithfully about his support.

\section{Authors' contributions}

WYK and GCF contributed equally to this article. WYK and GCF designed the project and wrote the manuscript. WYK, GCF, YT and CZ coordinated with data analysis and literature review. ZXW, LXX and MNL performed immunohistochemistry and FISH analyses. ZWZ provided clinical information. All authors have read and approved the final manuscript.

\section{Conflict of interest}

The authors declare that they have no competing interests.

Received: 18 November 2010 Accepted: 20 June 2011

Published: 20 June 2011

\section{References}

1. Sebastian S, Settleman J, Reshkin SJ, Azzariti A, Bellizzi A, Paradiso A: The complexity of targeting EGFR signaling in cancer: from expression to turnover. Biochim Biophys Acta 2006, 1766:120-39.

2. Chen $Q Q$, Chen $X Y$, Jiang YY, Liu J: Identification of novel nuclear localization signal within the ErbB-2 protein. Cell Res 2005, 15:504-10.

3. Nyati MK, Morgan MA, Feng FY, Lawrence TS: Integration of EGFR inhibitors with radiochemotherapy. Nat Rev Cancer 2006, 6:876-85.

4. Duffy MJ: Predictive markers in breast and other cancers: a review. Clin Chem 2005, 51:494-503.

5. Takai N, Jain A, Kawamata N, Popoviciu LM, Said JW, Whittaker S, Miyakawa I, Agus DB, Koeffler HP: 2C4, a monoclonal antibody against HER2, disrupts the HER kinase signaling pathway and inhibits ovarian carcinoma cell growth. Cancer 2005, 104:2701-8.

6. Dent R, Trudeau M, Pritchard KI, Hanna WM, Kahn HK, Sawka CA, Lickley LA, Rawlinson E, Sun P, Nayod SA: Triple-negative breast cancer: clinical features and patterns of recurrence. Clin Cancer Res 2007, 13:4429-34.

7. Wang YK: Fluorescence in situ hybridization: Gao CF. New technology and clinical laboratory diagnosis. 1 edition. Beijing: People's Medical Publishing House; 2010, 85-112.

8. Bang YJ, Van Cutsem E, Feyereislova A, Chung HC, Shen L, Sawaki A, Lordick F, Ohtsu A, Omuro Y, Satoh T, Aprile G, Kulikov E, Hill J, Lehle M, Rüschoff J, Kang YK: ToGA Trial Investigators. Trastuzumab in combination with chemotherapy versus chemotherapy alone for treatment of HER2-positive advanced gastric or gastro-oesophageal junction cancer (ToGA): a phase 3, open-label, randomised controlled trial. Lancet 2010, 376:687-97.

9. Varella-Garcia M, Diebold J, Eberhard DA, Geenen K, Hirschmann A, Kockx M, Nagelmeier I, Rüschoff J, Schmitt M, Arbogast S, Cappuzzo F: EGFR fluorescence in situ hybridisation assay: guidelines for application to non-small-cell lung cancer. J Clin Pathol 2009, 62:970-7.

10. Lenferink $A E$, Pinkas-Kramarski $R$, van de Poll ML, van Vugt MJ, Klapper $L N$, Tzahar E, Waterman H, Sela M, van Zoelen EJ, Yarden Y: Differential endocytic routing of homo and hetero-dimeric ErbB tyrosine kinases confers signalig superiority to receptor heterodimers. EMBO J 1998, 17:3385-3397.

11. Pérez-Soler R: HER1/EGFR targeting: refining the strategy. Oncologist 2004, 9:58-67.

12. Sakai K, Mori S, Kawamoto T, Taniguchi S, Kobori O, Morioka Y, Kuroki T, Kano K: Expression of epidermal growth factor receptors on normal human gastric epithelia and gastric carcinomas. J Natl Cancer Inst 1986, 77:1047-52.

13. Brabender J, Danenberg KD, Metzger R, Schneider PM, Park J, Salonga S, Hölscher AH, Danenberg PV: Epidermal growth factor receptor and HER2- neu mRNA expression in non-small cell lung cancer is correlated with survival. Clin Cancer Res 2001, 7:1850-5.

14. Penault-Llorea F, Cayre A: Assessment of HER2 status in breast cancer. Bull Cancer 2004, 91:S211-15.

15. Cao WG, Ma T, Li JF, Li H, Ji YB, Chen XH, Liu BY, Jin YN: Effect of gefitinib on radiosensitivity of gastric cancer cell lines. Ai Zheng 2007, 26:1330-5.

16. Reuter CW, Morgan MA, Eckardt A: Targeting EGF-receptor-signaling in squamous cell carcinomas of the head and neck. Br J Cancer 2007, 96:408-16.

17. Onn A, Correa AM, Gilcrease M, Isobe T, Massarelli E, Bucana CD, O'Reilly MS, Hong WK, Fidler IJ, Putnam JB, Herbst RS: Synchronous overexpression of epidermal growth factor receptor and HER2-neu protein is a predictor of poor outcome in patients with stage I nonsmall cell lung cancer. Clin Cancer Res 2004, 10:136-43.

doi:10.1186/1755-8166-4-14

Cite this article as: YK et al:: Assessment of ERBB2 and EGFR gene amplification and protein expression in gastric carcinoma by immunohistochemistry and fluorescence in situ hybridization. Molecular Cytogenetics 2011 4:14.

\section{Submit your next manuscript to BioMed Central and take full advantage of:}

- Convenient online submission

- Thorough peer review

- No space constraints or color figure charges

- Immediate publication on acceptance

- Inclusion in PubMed, CAS, Scopus and Google Scholar

- Research which is freely available for redistribution

Submit your manuscript at www.biomedcentral.com/submit
C Biomed Central 